\title{
The Influence of Digital Technology on the Trend of Museum Media
}

\author{
Weihang Xu $1^{\text {st }}$
}

\author{
Ming Chuan University \\ Email:weihangxu9@gmail.com
}

\begin{abstract}
As a social service institution with cultural and educational significance, the exhibition mode of museum should also keep pace with the times. In recent years, with the development of Internet and technology, the media trend of museums is also increasing. This paper is divided into three parts. Based on the communication theory, this paper analyzes the involvement of digital technology in museums, and finally discusses the impact of digital technology on the trend of Museum media.
\end{abstract}

Keywords: digital technology, museum, media.

\section{INTRODUCTION}

As a social service organization, museums collect and maintain objects of scientific, artistic or historical importance, and enable the public to see these objects through display. The functions can be summarized as follows: collection, research, exhibition and education. In the wave of informatization, the Internet and digital technology are developing rapidly. As an important information carrier, the museum is a special media. Through the construction and improvement of digitization, the media function of the museum has been further extended and expanded. For the museum itself, digitization is the processing, processing, storage, transmission and other information work of the collection information. The Louvre in France introduced digital technology into museums earlier abroad, such as the application of AR and VR technology. The domestic digital museum started gradually in the 1990s, and then entered the stage of rapid development. For example, in recent years, the exhibition methods of the Forbidden City Museum, such as virtual exhibits, visual interactive design, voice guidance and the launch of cultural and creative products, have not only increased the appreciation, but also mobilized the enthusiasm of the public, and effectively achieved the purpose of cultural publicity and education. The application of digital technology makes the museum break through the limitations of time and space and become "ubiquitous". At the same time, the interaction between the museum and people is strengthened by the development of media.
This also confirms McLuhan's media theory, that is, "media is the extension of the human body" [1]. In addition, he believes that" the electronic age is an era of synchronous and instantaneous communication, and also an era of instantaneous elimination of time and space" [1]. This paper will interpret the museum from the perspective of media and analyze the intervention of digital technology in the museum, so as to further explore the impact of digital technology on the trend of Museum media.

\section{MUSEUM FROM THE PERSPECTIVE OF MEDIA}

From the perspective of communication, there are two interpretations of media. The first refers to the carrier, channel, intermediary, tool or technical means of information transmission (language, books, newspapers, radio, television, computer, etc.); Second, it refers to social organizations engaged in the collection, processing, production and dissemination of information, which use media for storage and dissemination (such as publishing houses, newspapers, radio stations, television stations and various new media at present) [1]. There is no doubt that the museum is a carrier of information dissemination. In the past, exhibits were one of the important functions of museums. As an important medium for Museum communication, exhibits are essentially "a medium for information handling and enabling between different people, cultures and times. Through the museum organization and Museum process, they enter the information of the audience and the public from the past 
tense and the original background to the present or future era Knowledge and value systems" [2]. Museums convey information and culture to the public by displaying objects and have cross time and space significance. The development of the Internet and the progress of media technology provide us with a new perspective. The museum has become a comprehensive media. As McLuhan said, the media is the extension of the human body. Therefore, the museum is also the collective extension of human senses. From the perspective of media, the museum can not be separated from "things" from beginning to end. Things are the foundation of the museum. Use emerging technologies to make the display of objects more three-dimensional and vivid, so as to help people unlock their exclusive dusty memories, and then show them to the public in a novel way. One of the characteristics of hermeneutics is the immediacy and traversal. Although the interpreter and the interpretation object are in the present, in fact, the interpretation object was originally in another time and space, but now it is equivalent to meeting the interpreter through time and space. The interpretation object and the interpreter meet or meet at the present with their own historical exchange [3]. In McLuhan's media theory, he believes that "human beings will gradually lose their subjectivity and initiative, and all human activities and central nervous system will be controlled and dominated by media technology" [4]. Levinson, another scholar, believes that "the future media will be more and more humanized and make mankind more and more free" [4]. In addition, he proposed that humanization is in line with human ecology. In other words, the development of new media to the extreme of freedom is the future media [4]. Levinson believes that the media will continue to serve mankind and make human life more and more convenient. Therefore, his view is more inclined to take people as the main body. McLuhan's perspective is more long-term. He believes that the continuous convenience brought by emerging media will make human beings lose their dominant position, and finally human beings will be controlled by the media. From the current digital development of the museum, the innovation of technical means is to better serve the public, increase the public's understanding of the museum's exhibition content, enhance the interaction, and make the interaction become a new direction of the current museum development.

Ross parry, a British digital heritage expert, once said: "we can even say that the media defines museums. Between ancient and modern times, the museum will realize a variety of display forms and functions from the different communication technologies it chooses." [5] Museum is not just a museum. As a medium, it should not only give play to its own characteristics and communicate with human beings, but also take the exhibition as the center, but it cannot be limited to this. As a medium, it has a transcendence and creates a super space-time platform for people.

\section{THE INVOLVEMENT OF DIGITAL TECHNOLOGY IN MUSEUMS}

Museum is a historic landmark for people. With the development of technology, the previous display mode of "Exhibition+ showcase + panel" is no longer attractive, and it is difficult to meet the needs of contemporary audiences. So virtual museums and 3D exhibition halls began to emerge. ZhangHaoda, Professor of the Department of information management in Beijing, said: "the core value of digital museum is that it can easily and quickly obtain effective information of museum collections without the restriction of time and space" [6], the most essential thing is to transmit information and culture through technology.

At present, the digital technology intervention of domestic museums is mainly in and out of the museum. The digital intervention in the museum is mainly reflected in the digitization of exhibition resources, including the extraction and storage of words, pictures, sounds and images. In addition, new interactive media design is gradually introduced into the museum. In addition to the earlier voice interpretation and guidance, $\mathrm{AR}$ is also more and more widely used, mainly in the digital restoration technology and application of exhibits, AR presentation, vivid interpretation of historical situations, display design in the museum, simplified voice guidance function, etc.

In particular, the rapid development of $\mathrm{AR}$ and $\mathrm{VR}$ technologies has broken the technical barriers. Robert Hewison, a well-known British curator and scholar of humanities, said that "museums are not just storage places for objects; It is also a place for people to exchange ideas. Their future depends on the dynamic part of the remaining public sphere. The key to the survival of the museum is dynamics, and applications using new technologies such as augmented reality and image recognition may be the solution." In the past, when appreciating or visiting cultural relics, the public could only understand the historical scenes and stories at that time through a simple lifeless exhibition and some explanations. They could not be completely immersed in the cultural atmosphere and were not impressed. However, through the re shaping of $\mathrm{Ar}+3 \mathrm{D}$ modeling technology, the original static calligraphy and painting can also become vivid three-dimensional works. In addition, there are virtual interactions between historical figures. For example, the Taiwan Museum and Mr. fossil enterprises in Taiwan have jointly launched the "Taibo palm Museum", which is the first time that the Taiwan Museum has used the "indoor positioning and navigation system" to revive Paleontology and fossils, In the Museum of paleontology, people can have the same experience as the revival of museum exhibits in the film "Museum Night". The colorful AR technology not only makes the exhibits more vivid, but also allows the 
exhibits to interact with the audience, adding more interest and possibility to education.

The outside intervention of digital technology is mainly to break through the limitation of space. To this end, people first built the official website of the museum, including adding virtual tours, detailed map explanations, and customized private tour routes, which provided convenience for people who could not or had not arrived at the scene. Whenever and wherever possible, mobile phone mobile phone is emerge in an endless stream. At the same time, under the Internet environment, museums are gradually promoting different platforms, such as micro-blog, WeChat official account and mobile phone APP. In view of the gradual increase of people's dependence on mobile phones, various kinds of APP are emerging in an endless stream in order to make people understand the culture anytime and anywhere. For example, the "Han Xizai's banquet map" app was on the popular recommendation of the app store on the first day of its launch, which can be seen from its popularity. This is a unique app produced by the Palace Museum, which restores every detail of famous paintings and shows the style of the late Tang Dynasty to the public. With professional topic explanation, we have a deeper understanding of the historical background of famous paintings. The main core of digital construction outside the museum is people-centered to meet the needs of users. Mo Yang, associate professor of the science and technology communication research center of the Graduate School of the Chinese Academy of Sciences, said, "some digital museums do not fully embody the user-centered concept and do not provide different information interfaces and content services for different user groups. The focus of work is still on the extensive collection of website materials and the digital construction of physical collections, However, the construction of information resources is only the basic part of the work of digital museum, and the real focus of digital museum should be users." [5] It can be seen that the focus of digital museum is changing from "things" to "people", which requires the museum to consider the needs of users and design centered on users in the process of digital construction. How to structure the effective communication between living visitors and inanimate collection information is the key to the success of digital museum construction.

Although the development of technology makes the communication modes of museums more diversified, VR and AR technologies are not very popular. If people want to experience, they must go to professional museum sites. If they are at home, they need to buy VR equipment, which is easy to produce economic burden. The use methods of other professional equipment should also be mastered, which limits the scope of the audience to a certain extent and is easy to cause a new "information gap". Therefore, while digital technology is involved, museums should also improve the "media use ability" of the public in order to maximize the advantages of technology.

\section{THE INFLUENCE OF DIGITAL TECHNOLOGY ON MUSEUM MEDIA}

McLuhan put forward "hot and cold media theory" in his book understanding media [7], Cold and hot media is McLuhan's standard of media division. The discussion of cold and hot media plays an important role in McLuhan's theory. Media have no vitality, but McLuhan gives them temperature. He believes that the information of thermal media has high clarity, low uncertainty, low participation and exclusion; Cold media has low message clarity, high uncertainty, high participation and inclusiveness [7]. The museum has always given people the impression of being serious and solemn, carrying the weight of history. The museum presents the cultural relics or collections to the public in good condition in the exhibition cabinet, but the public can only understand the cultural relics through some cold text introductions, which makes the public feel that the distance between themselves and the cultural relics is still very far. From the perspective of hot and cold media, traditional museums belong to cold media. The information that cultural relics can express is only a part of the display cabinet. The clarity of the information is low. People need to mobilize a variety of senses for imagination, which inevitably makes the viewer feel boring and tasteless. However, with the intervention of digital technology, the museum has become a comprehensive medium. In order to let the public understand cultural relics in multiple dimensions, the museum adopts multimedia technology, "connecting various information media such as radio, television, (IP) telephone, electronic publishing and computer communication through digital compression and network, and And even three- dimensional data for integrated processing and display" [8], it improves the information clarity of cultural relics. Therefore, what the public see is no longer simple cultural relics and words. With the support of digital technology, the museum is gradually approaching the thermal media. In other words, the simple division of media is no longer applicable. With the development of digital technology, there will be more and more mixed media.

With the development of digitization, the museum not only changes the way of exhibition, but also changes its viewing groups, viewing methods and viewing places. Traditional museums are exclusive to a certain extent. Only a few people can visit the early museums, and their function of popular science education is not as significant as it is now. With the development of the times, the group watching the museum has changed from white-collar workers, elites and intellectuals to the general public. The change of audience and the differences between groups force the museum to constantly improve the display mode. 
Among all the changes, the most significant is the change of viewing mode, because the popularization of groups will also lead to the popularization of viewing behavior. In the traditional museum era, we look at cultural relics through our eyes, and our vision only stays at the appearance of physical objects. The development of new media has also changed the way we watch. The museum has not only digital presentation, but also digital interaction. As mentioned above, "AR + 3D modeling technology" has injected new vitality into the museum, so that the way people watch is no longer twodimensional. As the scholar Lacan said in the gaze theory, "the eye cannot see the gaze located on the object, and the seeing behavior of the eye cannot fully reflect the whole essence of visual practice. In the visual relationship, the object that depends on illusion and makes the subject suspended in a substantial swing is gaze." [9] Lacan reexamines the behavior of "viewing" from the perspective of visual culture. Traditional museums are more about browsing the pure movement emitted by the eyes, which is a kind of "static gaze" [8]. At present, the intervention of various media has diversified the viewing methods, made up for the lack of vision of people as the main body, and the things are more vividly presented in front of people, so as to complete the gaze on people. Before technology was involved, we always believed that the viewing of things was one-way, and people, the subject, watched to understand things. However, Lacan's gaze theory holds that "watch" is twoway. When people watch things, things are also staring at people, which shakes people's subjective position to a certain extent. Therefore, the involvement of digitization is beneficial to the development of museums, but in the digital wave, the future development direction of museums still needs to be considered.

\section{CONCLUSION}

As a special medium, museum is a place for people to communicate with history and culture. The development of digitization also brings people a new way to visit museums, which enhances the audience's immersive experience and stimulates more people's interest, so as to help cultural inheritance. In this process, the media trend of museums is gradually increasing, but how to maintain the accuracy, authenticity and integrity of communication information under this trend isalso a new problem faced by museums.

\section{REFERENCES}

[1] Guo Qingguang, The Communication Course. Beijing: China Renmin University Press, 1999, p.15.

[2] Cao Bingwu, "The media trend of museums and its practical significance," in Museum, vol.5, pp.8285,2019 .
[3] Zhang Zhiping, "Phenomenological analysis of interpretative phenomena," in Tianjin Social Science, vol.4, pp.42-50, 2018.

[4] Zheng Suxia, "Technology creates environment an investigation of McLuhan's thought", in Contemporary Communication, vol.2, pp.30- 32, 2006.

[5] Li Bin, "Media relations, media narrative and media ethics in museums," in Art Review, vol.3, pp.8594,2021.

[6] Yuan Yue, "Digital brings vitality to museums," in Science News, vol.000, pp.52-53,2010.

[7] M. McLuhan, Understanding Media: on the Extension of Human Beings. Trans. He Daokuan. Beijing: The Commercial Press, 2000, p.52.

[8] Jin Ruiguo, "Communication research of Digital Museum,” in Wenbo, vol.4, pp.94-96,2010.

[9] Tang Yonghua, "Foucault or Lacan: an investigation of gaze," in Literature\&Art Studies, vol.12, pp.519,2020 . 